\title{
Realidade Lacrimosa: o melodramático no documentário
} brasileiro contemporâneo

Juily Manghirmalani ${ }^{1}$

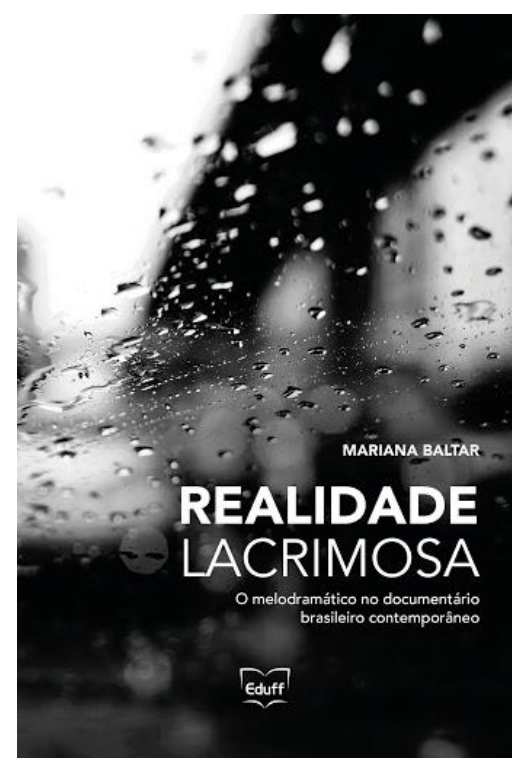

Resenha

Baltar, Mariana. Realidade Lacrimosa: o melodramático no documentário brasileiro contemporâneo. Niterói: Eduff, 2019, 314 p.

${ }^{1}$ Mestre em Imagem e Som, pela Universidade Federal de São Carlos (2016), com pesquisa sobre o cinema de diáspora indiano e gênero. Em paralelo, trabalha no setor audiovisual como produtora e diretora. 
O livro Realidade Lacrimosa: o melodramático no documentário brasileiro contemporâneo é resultado de questionamentos apresentados por Mariana Baltar na pesquisa que teve início em seu doutorado, em 2003, defendido em 2007, até o recém lançamento do livro em 2019.

Concomitante ao que João Luiz Vieira diz em sua contribuição à apresentação do livro, é de fato, perceptível a densidade do trabalho de Baltar. Ela aponta suas hipóteses e análises com profundidade ao pensar as produções documentais brasileiras em relação ao melodrama e à ultra valorização da intimidade, parte essa, de um projeto de modernidade estabelecido desde as mudanças sociais e políticas decorrentes da Revolução Industrial.

$\mathrm{Na}$ introdução, a autora exibe resumidamente o percurso que irá tecer no decorrer do livro, apresentando seu arcabouço teórico sobre os efeitos políticos do diálogo e o engajamento afetivo em moldes contemporâneos, como também, a seleção de filmes que analisa. Ela dedica-se, então, aos documentários que possuem diálogo com a imaginação melodramática para exibir questões relacionadas ao espaço público e privado dos personagens.

Como diz Baltar, sua pesquisa é feita de forma teórica-analítica, mas também, há o ofício de um levantamento histórico necessário para fundamentar a presença da leitura melodramática no formato documentário, o que ocorre desde a sua concepção como gênero cinematográfico.

A divisão feita para as análises dos filmes encontra-se em torno de dois eixos temáticos: o acesso à memória e o pacto de intimidade.

Com o apoio de pesquisas e conceitos cunhados por autores como Maurice Halbwachs (1990), Jacques Le Goff (1992) e Pierre Nora (1984 e 1988), Mariana Baltar apresenta interpretações sobre as performances do acesso à memória, como as realizadas nos filmes Ônibus 174 (2002), Um Passaporte Húngaro (2001) e Peões (2004). Essas obras possuem em comum a reconstrução de eventos através da lembrança, contados por personagens que presenciaram ou fizeram parte dos acontecimentos. O segundo eixo foca-se no pacto de intimidade ao trazer obras que apresentam a relação e diálogo entre diretor, personagem e público. Estão nessa abordagem os filmes A pessoa é para o que nasce (2003), Estamira (2004) e Edifício Master (2002).

Porém, antes de iniciar as análises dos documentários, a autora escolhe aprofundar a discussão teórica entre documentário e imaginação melodramática nos primeiros dois capítulos do livro. Sendo assim, encontra-se no capítulo um a pauta sobre os domínios do documentário e seus processos de legitimação da realidade e verdade; e no capítulo dois, as noções e conceitos desenvolvidos sobre a imaginação 
melodramática em um campo político, em que há questionamentos sintomáticos sobre o contexto da modernidade, na discussão entre as esferas do público e privado, a pedagogização dos sentimentos e suas narrativas.

Intitulado $O$ universo documentário - traçando as bases de uma "imaginação documental", o primeiro capítulo aborda cronologicamente a construção do gênero documentário. Ele percorre desde o fundador do termo, John Grierson, até as noções de documentário clássico, moderno e o contemporâneo, por meio de um levante histórico da emergência da figura do personagem como portador do discurso que traça a narrativa principal.

Um dos pontos mais importantes abordados por Baltar nesse capítulo está na configuração essencial do gênero documentário, como portador da legitimidade e da verdade em suas representações, ou seja, "pela ligação com a memória de um uso frequente associado aos discursos de explicação e definição do real, os quais acabam por 'induzir' o público a relacionar-se com a narrativa como representação da realidade" (BALTAR, 2019: p. 43).

Ao final do capítulo, a autora aponta como o cinema moderno brasileiro se aproximou mais das propostas francesas de documentário moderno e menos do cinema americano da época, o que trouxe uma predominância de filmes sobre encontros e seus processos de realização.

O segundo capítulo, nominado Imaginação melodramática - instâncias do privado e a pedagogia das sensações, se debruça sobre esse gênero narrativo que surge como modelo regularizador da nova moral no contexto da modernidade. Dentro do conceito de melodrama, há a nova valorização do cotidiano e da dicotomia entre privado e público, que acaba por criar uma narrativa enraizada em noções e morais conservadoras que reinstauram a noção do certo e errado em uma sociedade secular e capitalista.

Baltar, então, faz referência a autores cânones do melodrama, como Peter Brooks (1995), Thomas Elsaesser (1987) e Ben Singer (2001), como também se utiliza de reflexões advindas de Ivete Huppes (2000), Silvia Oroz (1992) e Ismail Xavier (2003) para argumentar que, além de gênero narrativo, o melodrama atua ainda como uma percepção de mundo e regularizador social no projeto de modernidade.

Após essas considerações, o capítulo segue para uma compreensão de como - melodrama atua em narrativas audiovisuais. As categorias de análise foram selecionadas através de identificações e recorrências que permeiam a imaginação melodramática, mais do que o gênero clássico em si. São essas: a antecipação, a simbolização exacerbada e a obviedade. As três são utilizadas como estratégia narrativa de engajamento para que o público identifique rapidamente as polaridades moralizantes, 
as divisões entre o bem e o mal, o julgamento social e quais problemáticas o detentor das boas virtudes deve superar para ter o aclamado "final feliz".

Por fim, ainda nesse capítulo, Baltar aponta para o cinema de ficção - que já mistura formatos, gêneros e linguagens, utilizando em muito dos moldes melodramáticos em sua construção. Com isso, expõe sua percepção de que há também um atravessamento para o gênero não ficcional, a partir de uma certa recorrência de produções de documentários brasileiros dos anos 2000 que dialogam com esse projeto de modernidade.

As análises começam a partir do terceiro capítulo. Em Memória - conexões privadas e públicas num elo afetivo, a autora abarca conceitos de memória individual e coletiva, para também falar da construção da memória histórica. $O$ argumento é disposto em cima da busca por legitimidade apreendida nas memórias coletivas que acabam por reforçar laços afetivos através do compartilhamento.

Os filmes analisados nesse capítulo trabalham em cima da evocação da memória e da utilização de imagens que manipulam a reconstrução de eventos, seja pelas múltiplas narrações de um ocorrido - caso de Ônibus 174, em que a mudança de ângulo sobre $o$ incidente faz com que o assaltante passe de criminoso à vítima do sistema; por meio de imagens transpostas de diferentes subjetividades em Um Passaporte Húngaro, em que há a reconstrução de uma trajetória de vida geracional e territorial; ou por imagens de arquivo que autenticam as falas - caso de Peões, onde um momento histórico é contado por parte dos construtores do movimento político da época.

As recordações acionadas nesses filmes são feitas por meio de testemunhos dos personagens que estiveram presentes nos momentos recordados, ou depoimentos, onde a memória incorpora uma visão coletiva e é compreendida através do sujeito em si e em sociedade. Nesse, a interligação do privado e público é feita através do que autora nomeia como engajamento afetivo, procedente da comoção recordada nas ações narrativas, que estariam então, corrompidas pela imaginação melodramática.

No capítulo seguinte, Intimidade em duas vias - tema e estratégia, Baltar traz a relação da performance de si e a negociação, muitas vezes não perceptíveis no filme, do processo de se auto constituir como personagem em frente à câmera. Os argumentos, portanto, giram em torno de duas instâncias: a intimidade e a negociação.

A autora chama de pacto de intimidade a estratégia de autenticidade e legitimação presentes nesses filmes contemporâneos, entre as relações criadas entre ator social, diretor/equipe e espectador.

Centrada na figura do personagem, o documentário contemporâneo utiliza da intimidade que se estabelece como moeda de legitimação da verdade, onde o pacto central do filme é instaurado. As noções de realidade e da vida exterior, são, então, 
apreendidas pela relação dos personagens e das suas histórias de vida. A importância da vida privada e o valor da intimidade acabam por ganhar um poder significativo nos desenvolvimentos do projeto de modernidade. E, dentro da lógica mercantil, a autora coloca como aspecto crítico como esse pacto não é só afetado pela modernidade, como também, é instrumentalizado através da negociação entre as dinâmicas sociais e éticas que envolvem essa troca.

Essa negociação que ocorre na esfera da realização documental trabalha também como uma noção de embate entre as performances dentro de um contexto midiático contemporâneo já estabelecido, em que os indivíduos "representam, performam para as câmeras do documentário os papéis sociais de si" (BALTAR, 2019: 223). A autora comenta que a expressão performance de si aparenta um certo pleonasmo, mas que se torna necessário pois

Trata-se da consciência de que, ao serem convocados a falar de aspectos da vida privada, em especial no que concerne ao cotidiano, operam, através da performance, uma exposição de si, do que é da ordem da intimidade. Essa troca de intimidades é o que está sendo demandada pela narrativa, e os sujeitos, atravessados pela sociedade midiática, parecem ter domínio desse código, atendendo a essa demanda. (BALTAR, 2019: 226).

Em A Pessoa é para o que nasce (2003), Baltar apresenta como o registro e a edição trabalharam de forma crescente a relação entre as três personagens cantoras com o diretor, em paralelo à cronologia do anonimato até a fama.

$\mathrm{Na}$ análise de Estamira (2005), Baltar aponta que o diretor não se faz visualmente presente, aparecendo somente em uma fala ao final do filme. Nesse caso, a relação personagem e câmera é a estratégia de aproximação e engajamento com a personagem. Tanto a forma pela qual Estamira interage com o dispositivo, como também a forma com que a equipe aborda as conversas, com o uso excessivo de planos fechados e próximos do corpo da personagem.

Já em Edifício Master (2002), Baltar analisa que esse filme desconstrói as fáceis identificações da configuração melodramática. Para ela, há uma certa frieza e distanciamento do aparato fílmico com os personagens. Porém, como a autora escreve, os filmes de Coutinho, em especial Edifício Master (2002) e Peões (2004), convidam a um nível de diálogo com a imaginação melodramática mais crítico e potencialmente interessante, para pensarmos diversos aspectos da 
formação da subjetividade contemporânea. (BALTAR, 2019: 230).

Para a autora, uma das forças presente nesse filme e em outros de Eduardo Coutinho é a própria exposição da consciência dos personagens, dentro da noção de sociedade do espetáculo, sobre sua auto performance como um possível tema subliminar dos filmes.

Após as investigações em cima dos documentários propostos, Mariana Baltar conclui o livro com um apanhado do processo de construção dessa obra, reiterando o local de fala dos personagens e suas apropriações através dos pactos de intimidade. Ela pontua, ainda, que há a possibilidade de pragmatismos na utilização da imaginação melodramática em documentários. Isso ocorre, por exemplo, em filmes como os de Eduardo Coutinho, quando a obra apresenta um projeto político e estético que transparece na tela e no discurso, e que nem sempre busca equalização com o universo exposto. Com isso, acaba por evitar a formulação e até a manutenção de tons moralizantes e pedagógicos de representações de vivências e sentimentos. Em vez, apresenta uma possível partilha no campo da alteridade, abrindo espaço para a capacidade de exposição do outro sem a presença paternalista do realizador, mas sim uma viável alternativa de caminhada paralela. 